\title{
Avian bornavirus in the urine of infected birds
}

This article was published in the following Dove Press journal:

Veterinary Medicine: Research and Reports

16 June 2012

Number of times this article has been viewed

J Jill Heatley'

Alice R Villalobos ${ }^{2}$

'Zoological Medicine, ${ }^{2}$ Department of Nutrition \& Food Science, Texas A\&M University, College of Veterinary Medicine and Biomedical Sciences, College Station, TX, USA
Correspondence: J Jill Heatley Zoological Medicine, Texas A\&M University, College of Veterinary Medicine and Biomedical Sciences, College Station, TX, USA

Tel + I 979854 I202

Fax + I 9798456978

Email jheatley@cvm.tamu.edu
Abstract: Avian bornavirus (ABV) causes proventricular dilatation disease in multiple avian species. In severe clinical disease, the virus, while primarily neurotropic, can be detected in many organs, including the kidneys. We postulated that ABV could be shed by the kidneys and found in the urine of infected birds. Immunohistochemical staining demonstrated viral $\mathrm{N}$ and $P$ proteins of $A B V$ within the renal tubules. We adapted a nonsurgical method of urine collection for use in parrots known to be shedding ABV in their droppings. We obtained urine without feces, and results were compared with swabs of fresh voided feces. Reverse transcription-polymerase chain reaction assay performed on these paired samples from five birds indicated that $A B V$ was shed in quantity in the urine of infected birds, and a single sample was urine-positive and fecal-negative. We suggest that urine sampling may be a superior sample for detection of birds shedding ABV, and advocate that additional birds, known to be shedding or infected with ABV, should be investigated via this method.

Keywords: avian bornavirus, Psittaciformes, parrot, urine, proventricular dilatation disease

\section{Introduction}

Avian bornavirus (ABV) is a cause of proventricular dilatation disease (PDD) in many bird species, but predominantly in the order Psittaciformes. ${ }^{1,2}$ It is a negative-stranded RNA virus that uniquely replicates within the cell nucleus. ABV can cause a severe encephalomyelitis. However, in many cases, the virus spreads to the enteric ganglia. As a result of myenteric ganglia destruction, atony of the proventriculus and other regions of the gastrointestinal tract, PDD results in slowing and cessation of food passage, impaction, and proventricular dilatation. Many infected birds die as a result of starvation or secondary bacterial infection. Immunohistochemistry (IHC) of ABV-infected birds has shown that the virus is not restricted to the nervous system. In fact, it commonly spreads to all the major organs, including heart, liver, adrenals, and the kidneys. ${ }^{1,3-5}$

Birds infected with $\mathrm{ABV}$ have an incubation period that may range from 20 days to several years. ${ }^{6}$ For much of this time, the birds may appear healthy but shed the virus through their choana, nares, and droppings. The presence of the virus may be detected by reverse transcription-polymerase chain reaction (RT-PCR) assay, either directly from the droppings or from a cloacal swab. However, shedding is intermittent and varies greatly between individuals. Some birds shed almost constantly, while others shed at infrequent intervals. ${ }^{2}$ Most sources consider the most likely method of viral transmission as fecal/oral, with virus assumed to be excreted in the feces. ${ }^{1,5}$ However, we postulate that in fact ABV may be more likely to be spread via a urinary route. Multiple researchers have described the presence of ABV within the kidney, in 
PDD-affected and ABV-infected birds via PCR and immunohistochemical staining. ${ }^{4,5,9}$ Indeed, some have postulated that ABV may be transmitted via the kidney or urine. ${ }^{5}$

Avian droppings consist of a mixture of feces and urine. Both are delivered to the cloaca from the ureter and intestine and then excreted as a mixture. In birds, urine flows back into the coprodeum and colon for postrenal handling of urine, an important part of water and electrolyte osmoregulation in avian species. Urine consistency varies depending on species, but occurs as a suspension of urate crystals and mucopolysaccharide microsphere complexes wherein uric acid is present in concentric layers. When droppings are sampled, the sample obtained invariably consists of a mixture of feces and urine. In this paper, we describe a method of sampling urine separately as a preferred sample for the detection of the shedding of ABV.

Our objectives for this brief study were: (1) to develop and assess the feasibility of a novel technique for obtaining urine from parrots; (2) to assess urine from parrots known to be shedding $\mathrm{ABV}$ for the presence of $\mathrm{ABV}$; (3) to compare PCR of urine and fecal swabs from these birds; and (4) to present immunochemical stain findings of a previous study that also support our hypothesis.

\section{Materials and methods}

This was a simple prospective observational study of birds obtained by donation to the Schubot Exotic Bird Health Center. Urine samples were collected from five birds naturally infected and known to be shedding ABV in their droppings as determined by RT-PCR assays of fecal swabs. Birds sampled consisted of two African grey parrots (Psittacus erithacus), one scarlet macaw (Ara macao) one blue-headed parrot (Pionus menstruus), and one military macaw (Ara militaris). Gender was not determined for these birds. The clinical status of these subjects was beyond the scope of this study, and based on the small sample size, no statistical analysis was performed.

Urine samples were obtained from live birds according to the method previously described that uses polyethylene microtubes as collection cannulae. ${ }^{7}$ This method was modified to collect urine from macaws and smaller parrots as follows. In $300-\mu \mathrm{L}, 600-\mu \mathrm{L}$, and $1500-\mu \mathrm{L}$ snap-cap microtubes, small windows $\left(3,5\right.$, or $7 \mathrm{~mm}^{2}$, respectively) were cut near the top of the tube approximately $90^{\circ}$ left or right of the cap hinge. The cap remained attached to the tube and was used to guide the insertion of the closed end of the tube into the cloacal vent and subsequently position and hold the window over the ureteral papilla for collection of urine. However, the closed end of the microtube prevented contamination by intestinal contents and fecal matter during urine collection (Figure 1). To collect urine, birds were anesthetized to a medium plane of anesthesia with sevoflurane administered via face mask to facilitate handling and cloacal relaxation. Birds were suspended ventrodorsally with wings slightly extended, as if perched with the feet resting on a rolled towel. After positioning of the appropriately sized microtube inside the cloacal vent, urine flowed from the urogenital papilla by gravity through the window and directly into a PCR tube or into a microhematocrit capillary tube to a PCR tube.

For comparison, four of the fecal samples were obtained by swabbing the brown portion of a fresh dropping. For one bird, feces contained in the coprodeum on postmortem examination was swabbed. Although urine contamination is assumed with these methods of collection, this method was thought to mimic most closely the collection method of the general veterinary practitioner. Samples were collected and stored at $4^{\circ} \mathrm{C}$ for less than 48 hours prior to analysis.

\section{RNA purification}

As previously described, from each sample total RNA was extracted. ${ }^{8}$ Briefly, for fecal samples, the swab was flushed with $0.2 \mathrm{~mL}$ phosphate buffered saline. No additions were made to the urine samples. Approximately $140-\mu \mathrm{L}$ aliquots were removed and clarified by centrifugation at $12,000 \mathrm{~g}$ for 2 minutes. Total RNA was isolated from $140 \mu \mathrm{L}$ of clarified supernatant using the Qiagen (Hilden, Germany) Viral RNA Minikit based on the manufacturer's instructions, and total RNA was eluted in $40 \mu \mathrm{L}$ of elution buffer. First-strand cDNA was generated using the Applied Biosystems (Foster City, CA) High Capacity cDNA Reverse Transcription Kit, with $10 \mu \mathrm{L}$ RNA and random primers. The final composition of the cDNA reaction mixture was $2 \mu \mathrm{L}$ of $10 \times$ buffer, $2 \mu \mathrm{L}$ of $10 \times$ random primers, $0.8 \mu \mathrm{L}$ of $10-\mathrm{mM}$ deoxyribonucleotide triphosphate mix, $1 \mu \mathrm{L}$ RNAse inhibitor, and $1 \mu \mathrm{L}$ RT in a volume of $20 \mu \mathrm{L}$.

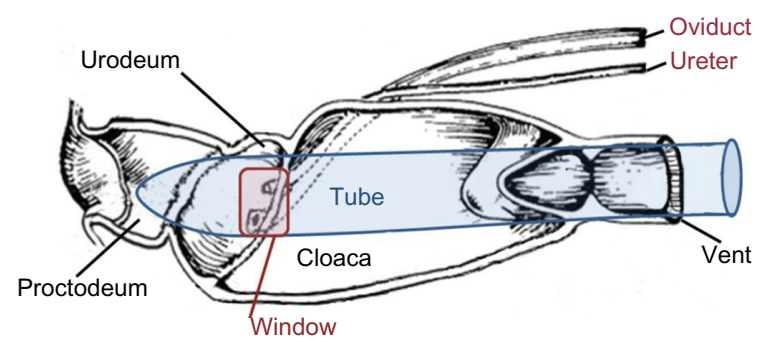

Figure I Diagrammatic representation of tube placement in the avian cloaca for collection of urine. 


\section{RT-PCR analysis}

Samples were analyzed for presence of nucleoprotein $(\mathrm{N})$ and matrix (M) protein gene expression as determined by RT-PCR analysis. A 5- $\mu \mathrm{L}$ aliquot of each cDNA sample was amplified by PCR using forward and reverse primers for each gene of interest. ${ }^{8}$ For intestinal contents, fecal or urine PCR, ABV sequences were amplified using two multiplexed primer sets. One recognized M-protein genes; the other recognized conserved regions of the $\mathrm{N}$ genes. The N-protein primer set was: forward $\left(5^{\prime} \mathrm{CAGACAG}\right.$ CACGTCGAGTGAGA 3) and reverse (5'GGCTCTTG GTCT GAGATCATGGAA 3). The M-protein primer set was: forward (5'-GGTAATTGTTCCTGGATGGC-3) and reverse (5'-ACACCAATGTTCCGAAGACG-3). The PCR conditions were as follows: initial denaturation, $94^{\circ} \mathrm{C}$ for 3 minutes, followed by 35 cycles of $94^{\circ} \mathrm{C}$ for 30 seconds, $54^{\circ} \mathrm{C}$ for 30 seconds, and $72^{\circ} \mathrm{C}$ for $20 \mathrm{sec}$, followed by a final extension of 5 minutes at $72^{\circ} \mathrm{C}$. PCR products were analyzed by agarose gel electrophoresis.

\section{Immunohistochemistry}

For further support of our hypothesis, we also submit an additional previously unpublished image from a cockatiel of a previous study. IHC was performed according to the method described by Weissenbock using a polyclonal crossreactive antibody against recombinant borna disease virus polymerase protein (BDVP) on cockatiels in which the disease was induced. ${ }^{4}$

\section{Results}

Results of RT-PCR for $\mathrm{M}$ and $\mathrm{N}$ viral proteins demonstrate that $\mathrm{ABV}$ is shed in the urine of infected birds (Figures 2 and 4). Note that for one bird, the urine lane is positive, while the fecal lane is negative (Figure 2). Therefore, $4 / 5$ birds are positive on fecal swab testing, while $5 / 5$ are positive on urine/ urates testing. IHC of a cockatiel experimentally infected with $\mathrm{ABV}$, strain M24, genotype 4 clearly demonstrates the presence of BDVP in the kidney of an affected bird. ${ }^{4}$ The presence of BDVP with cells and associated cellular debris within the tubular lumen is consistent with the presence of cell-associated viral shedding in the urine (Figure 3).

\section{Discussion}

Our previously unpublished image, from a previous study on ABV-4-infected cockatiels, demonstrates the presence of large amounts of BDVP protein with the cells, free within the lumen of the renal tubule. ${ }^{4}$ Virus escaping these cells would gain immediate access to the urine. Alternately, tubular cells

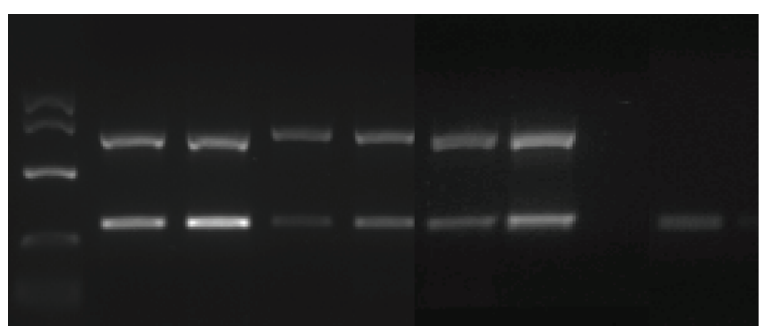

$\begin{array}{lllllllll}1 & 2 & 3 & 4 & 5 & 6 & 7 & 8 & 9\end{array}$

Figure 2 Expression of avian bornavirus (ABV) nucleoprotein and matrix protein genes in fecal and ureteral urine samples obtained from ABV-infected birds.

Notes: Lane I: molecular weight marker. Lanes 2-9 show the polymerase chain reaction (PCR) products using two primer sets; the upper band is a matrix protein PCR product, and the lower band is a nucleoprotein product. Lane 2: African grey I - feces. Lane 3: African grey I - urine. Lane 4: African grey 2 - feces. Lane 5: African grey 2 - urine. Lane 6: scarlet macaw 24 - feces. Lane 7: scarlet macaw $24-$ urine. Lane 8: pionus - feces. Lane 9: pionus - urine.

shed in the lumen and excreted as urine could be a source of viral DNA. Mammalian bornavirus disease is believed to be similarly transmitted in the urine of shrews. ${ }^{10,11}$ These concepts prompted us to investigate the collection of avian urine and to test urine via PCR for ABV RNA.

Based on our positive urine PCR results, findings of ABV within the kidney, and the image presented, we suggest that $\mathrm{ABV}$ could be transmitted via the urine of infected birds. However, as fluid was collected from the area of the urinary as well as genital openings into the urodeum, we cannot rule out that contamination of urogenital fluids may have also occurred and contributed to the PCR positive results. Seminiferous tubules were found to be positive for viral proteins in our studies, and recent reports of $\mathrm{ABV}$ presence in eggs (as well as our own unpublished findings) suggest that vertical transmission occurs for $\mathrm{ABV}^{4,12}$ The gender of birds

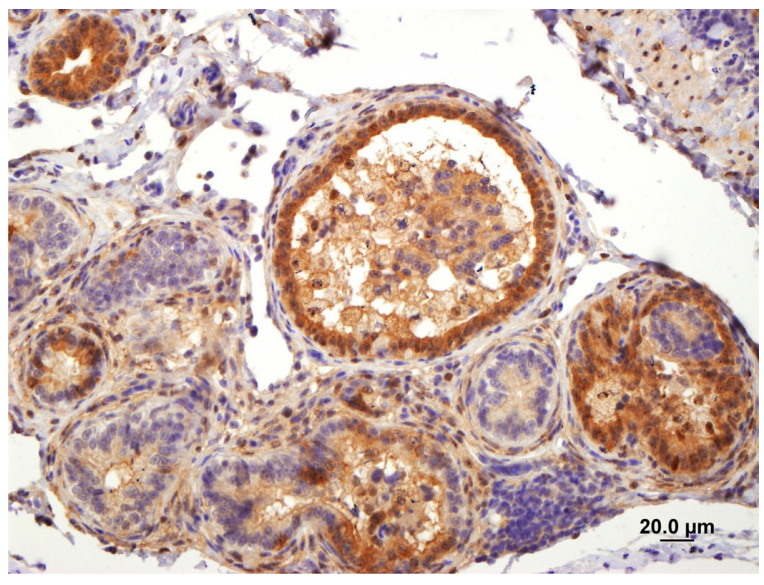

Figure 3 Immunohistochemical staining for borna disease virus polymerase protein in the kidney.

Notes: Viral antigen (brown) is present in large amounts in renal tubular cells, and positive cells are clearly visible within the lumen of the tubule. 


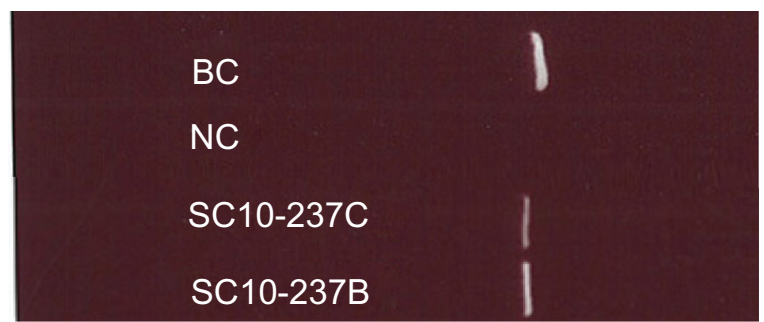

Figure 4 Expression of avian bornavirus ( $A B V$ ) matrix (M) protein genes in fecal and ureteral urine samples obtained from an ABV-infected military macaw (Ara militaris) based on reverse transcription-polymerase chain reaction analysis.

Notes: Lane I (BC): positive control for the M protein. Lane 2 (NC): negative control. Lane 3 (SCI0-237C): fecal sample collected postmortem via swab from the coprodeum. Lane 4 (SCI0-237B): urine sample collected postmortem from aspiration of the ureter.

was not determined for this study. Therefore, whether males or females may be more likely to have ABV in their urine, feces, or genital-tract fluids cannot be stated at this time.

Given that PDD is a disease that clinically affects the gastrointestinal tract, it has generally been assumed that the route of transmission of this virus was fecal-oral. ${ }^{2,13}$ Therefore the choanal/cloacal swab or fecal swab has been presumed the sample of choice for detection of ABV shedding. The presence of $\mathrm{ABV}$ in the droppings of $\mathrm{ABV}$-infected birds as detected by RT-PCR is well recognized. The gold standard for diagnoses of PDD remains crop biopsy and histopathological examination for detection of perinerve infiltrates. Our study shows that ABV is shed in significant, detectable amounts in urine and that birds may be PCR-negative on fecal swab and PCR-positive for ABV in collected urine. Both the $\mathrm{N}$ and $\mathrm{M}$ protein gene sequences were detected in the feces of most birds infected with ABV but in the urine of every infected bird. Our study shows that urine collection is just as viable, if not superior, to other sampling methods for detection of ABV shedding via PCR.

This preliminary study has a small sample size and multiple other limitations. We recognize that avian feces, whether collected from the colon, coprodeum, or from a voided sample are contaminated with urine, as part of normal avian physiology. Thus, complete separate sample testing via PCR of urine and feces is a very difficult goal to achieve in a clinical, noninvasive manner. While PCR product bands appear "brighter" as if in greater amounts in many of the urine lanes in our image, a quantitative comparison cannot be made between the sample sources. Urine is a liquid slurry, while feces are a semisolid that must be diluted from the swab for extraction of viral RNA. Quantitative PCR would be additionally necessary. However, we recommend further research to quantify $\mathrm{ABV}$ in urine, feces, and upper gastrointestinal tract contents without urine contamination to further assess viral shedding at differing sites. Similarly, separation and testing of genital fluids would also be recommended. However, these studies are likely to take a significant time and monetary investment for collection of samples, and may require study-subject death. Our goal was to create a clinical sampling technique useful in the ABV-infected patient.

This method of urine collection is more invasive, costly, and time consuming that a simple choanal, cloacal, or fecal swab. Further, this method of urine collection requires some training, some modified equipment, and is not sterile. However, we suggest that the potential to degrade viral RNA prior to detection via PCR is less with urine collected in this clean manner, compared to the classically employed sampling methods. Although designed to collect urine for determination of ABV shedding via PCR, this method's use could be expanded to give more insight into clinical urinalysis in birds, particularly when other forms of kidney disease are expected.

We do not recommend this method of urine collection for use in birds that may have their gastrointestinal, urinary, or reproductive systems affected by disease that may cause anatomical or physiological changes to the cloacal anatomy. These types of disease could include, but not be limited to, papillomatosis, neoplasia, or bacterial infection affecting the cloaca, reproductive, or urinary systems. These diseases could change the ability to collect urine cleanly based on damage or colonization to the urinary openings or changes in local anatomy obscuring the urinary opening or making tube placement a concern for further damaging local tissue. Persistent cloacal prolapse would also be a contraindication for this technique.

Positive aspects of this sampling technique are also many. We suggest that urinary sampling of urine and urates may be superior and should be considered as a sampling method in birds that are minimally clinically affected or intermittently shedding ABV. We suspect increased shedding of virus in urine/urate rather than feces. A collection with minimal fecal contamination could prevent viral RNA degradation based on fewer RNAase enzymes present prior to PCR testing. Thus this technique may be most clinically useful in ABV-suspect birds with previously negative PCR results from standard testing methods (choanal/cloacal swab). Further, this method would not require the time or cost of surgery, histopathology, or patient healing associated with biopsy. Finally, biopsy may only identify end-stage PDD, and while it is still considered the gold standard of diagnosis of PDD, it may certainly miss cases of ABV based on lack of histopathologic changes in general or specifically at the biopsy site, despite patient shedding of ABV. 
There can be no doubt that at this time the diagnosis of ABV shedding, while not equivalent with PDD, is important for avian management regarding sale, movement, acceptance, quarantine, and housing of infected birds. A false-negative result could have significant negative consequences for bird collections. Certainly, a positive determination for $\mathrm{ABV}$ does not warrant a diagnosis of PDD, which is a clinical syndrome. Birds infected with ABV may or may not develop PDD; similarly, birds affected by PDD may or not shed ABV. We do not advocate the diagnosis of PDD based on ABV shedding solely, as PDD is a clinical syndrome that may or may not occur when or if ABV shedding occurs. However, the method we describe is less invasive, less costly, and less time consuming than the gold standard for diagnosis of PDD: crop biopsy and histopathology. No postoperative healing time is required.

Therefore, we advocate the collection of urine and the continuing investigation and validation of this technique for the diagnosis of ABV infection based on multiple reasons. The presence of RNAase in feces or fluids of the oral cavity may increase the likelihood of viral RNA degradation and false-negative PCR outcome. The physical characteristics of urine, being liquid, are more amenable to PCR methodology, limiting the necessity of dilution of material from a swab that may also reduce viral RNA below the limit of detection, giving a false-negative result. Again, we believe this virus to be predominantly shed in the kidney based on our IHC and PCR data, making this sample more likely to be positive; whereas feces or cloacal swabs may or may not be positive based on the amount of urinary contamination (more likely), RNAase activity (less likely), and urine dilution with feces (less likely). Again, the finding of a single bird positive on urine but negative on feces supports this hypothesis. We recommend continued clinical diagnostic sampling of urine to further investigate the shedding of $\mathrm{ABV}$ and transmission of $\mathrm{ABV}$.

\section{Acknowledgments}

Immunohistochemical staining of borna disease virus polymerase protein (BDVP) was kindly performed by
Dr Weissenbock of the University of Vienna, Austria. Our sincere gratitude also goes to Guo Jianhua for all PCR analysis. Special thanks to Dr Ian Tizard for research support of this idea from the Schubot Exotic Bird Health Center.

\section{Disclosure}

The authors report no conflicts of interest in this work.

\section{References}

1. Honkavuori KS, Shivaprasad HL, Williams BL, et al. Novel borna virus in psittacine birds with proventricular dilatation disease. Emerg Infect Dis. 2008; 14:1883-1886.

2. Hoppes S, Gray PL, Payne S, et al. The isolation, pathogenesis, diagnosis, transmission, and control of avian bornavirus and proventricular dilatation disease. Vet Clin North Am Exot Anim Pract. 2010;13:495-508.

3. Lierz M, Hafez HM, Honkavuori KS, et al. Anatomical distribution of avian bornavirus in parrots, its occurrence in clinically healthy birds and ABV-antibody detection. Avian Pathol. 2009;38:491-496.

4. Payne S, Shivaprasad HL, Mirhosseini N, et al. Unusual and severe lesions of proventricular dilatation disease in cockatiels (Nymphicus hollandicus) acting as healthy carriers of avian bornavirus (ABV) and subsequently infected with a virulent strain of ABV. Avian Pathol. 2011;40:15-22.

5. Raghav R, Taylor M, Delay J, et al. Avian bornavirus is present in many tissues of psittacine birds with histopathologic evidence of proventricular dilatation disease. J Vet Diagn Invest. 2010;22:495-508.

6. Kistler AL, Smith JM, Greninger AL, et al. Analysis of naturally occurring avian bornavirus infection and transmission during an outbreak of proventricular dilatation disease among captive psittacine birds. J Virol. 2010;84:2176-2179.

7. Goldstein DL, Braun EJ. Structure and concentrating ability in the avian kidney. Am J Physiol. 1989;256:R501-R509.

8. Gray P, Hoppes S, Suchodolski P, et al. Use of avian bornavirus isolates to induce proventricular dilatation disease in conures. Emerg Infect Dis. 2010;16:473-479.

9. Rinder M, Ackermann A, Kempf H, et al. Broad tissue and cell tropism of avian bornavirus in parrots with proventricular dilatation disease. J Virol. 2009;83:5401-5407.

10. Hilbe M, Herrsche R, Kolodziejek J, et al. Shrews as reservoir hosts of borna disease virus. Emerg Infect Dis. 2006;12:675-677.

11. Puorger ME, Hilbe M, Muller JP, et al. Distribution of borna disease virus antigen and RNA in tissues of naturally infected bicolored whitetoothed shrews, Crocidura leucodon, supporting their role as reservoir host species. Vet Pathol. 2010;47:236-244.

12. Lierz M, Piepenbring A, Herden C, et al. Vertical transmission of avian bornavirus in psittacines. Emerg Infect Dis. 2011;17:2390-2391.

13. Gancz AY, Clubb S, Shivaprasad HL. Advanced diagnostic approaches and current management of proventricular dilatation disease. Vet Clin North Am Exot Anim Pract. 2010;13:471-494.
Veterinary Medicine: Research and Reports

\section{Publish your work in this journal}

Veterinary Medicine: Research and Reports is an international, peer-reviewed, open access journal publishing original research, case reports, editorials, reviews and commentaries on all areas of veterinary medicine. The manuscript management system is completely online and includes a very quick and fair peer-review system.

\section{Dovepress}

Visit http://www.dovepress.com/testimonials.php to read real quotes from published authors. 